\title{
The Synergetic Study of Rural Tourism Development: The Case of Chengdu City
}

\author{
Yan $\mathrm{Liu}^{1, *}, \mathrm{Bo} \mathrm{Pu}^{2}$, Zhenzhong Guan ${ }^{3}$ and Qizhi Yang ${ }^{4}$ \\ ${ }^{1,3}$ College of Tourism, Sichuan Agriculture University, Chengdu, Sichuan, 611830, China $;{ }^{1,2,4}$ School of Economics and \\ Management, Southwest Jiaotong Universtiy, Chengdu, Sichuan, 610031, China
}

\begin{abstract}
The development of rural tourism can enhance the regional economic development; improve the environment of the countries and the living conditions of the native dweller. In China, the study of countryside tourism mainly focuses on the microcosmic. However, as the progress of countryside tourism is a systematic issue, it should be studied systematically. From the view of Systematics and Synergetics, this thesis analyses the sub-systems in the development of countryside tourism in Chengdu. Based on this, an evaluation index system and a synergetic model are built for the development of countryside tourism in Chengdu, and relevant data from the year of 2003 to 2012 is studied for verification. The result shows that the sub-system of the countryside tourism industry in Chengdu is under fast development, but the synergetics of the sub-systems is as pitiable as imbalanced. In the end, against the synergetic current situation of countryside tourism development in Chengdu, this thesis provides policy advices for the government.
\end{abstract}

Keywords: Coordinated development, rural tourism, synergetic degree.

\section{INTRODUCTION}

Chengdu, has been awarded "the farmhouse birthplace" by the China National Tourism Administration in 2006. Rural Tourism in Chengdu develops rapidly, it has been basically formed a farmhouse, a national agricultural tourism demonstration sites, agricultural industrial base, tourism town, forest Park is the main form of rural tourism development pattern [1]. Rural tourism refers to all types of countryside background rural farming area and related customs, scenery, customs, scenery rustic combination of attraction to attract tourists go rest, sightseeing and learning experience of tourism activities [2]. Many scholars believe that the development of rural tourism is an important way to Harmony of urban and rural areas, rural tourism can broaden the channels for farmers' income, increase employment opportunities for farmers and rural areas to enhance the degree of civilization, is an important means of building a new socialist countryside is an important way for farmers to get rich is to make urban and rural people to share an important carrier of rural civilization, an important part of modern life in urban and rural residents' health.

Those researches about system theory explain that system is composed of several components of the combination between the interaction and interdependence with specific functions into an organic whole. There is a system of matter, energy and information flow [3]. Rural tourism development involves many factors and subsystems, according to the expanding of bucket theory, the development of rural tourism system should not only review their.
Technology and economy, business, and management studies [4]. own development of the various subsystems, they should consider the degree of coordination between the various systems. Therefore, this study based on the theory of collaborative learning, building collaborative degree of rural tourism development model to analyze the various subsystems of the collaborative development of rural tourism in Chengdu, Chengdu, according to the results of the analysis of the current development of rural tourism in the short board issues and make recommendations.

\section{LITERATURE REVIEW}

\subsection{Synergy and Synergetics}

As early as 1984 , Haken had claimed that synergetics is a rather field of interdisciplinary research and can be of some service to the management subject [5]. Knyazeva advocated that synergetics will go for a wide application field such as modern management [3]. Many researchers paid great attention to the synergy. This theory has been used in the environmental management, occupational health, and safety management systems. Besides, Rofiqul Islam et al., studied the synergy on the recovery and renewable resources and the technical substitution [6]. Pu studied the synergy between city human resources and city economy development based on the city marketing. To sum up, these studies try to use synergetics in management research but have yet to be further applied in technology and economy, business, and management studies [6].

\subsection{Rural Tourism}

In recent years, the rural tourism research's interest focused on the basic theory of rural tourism, the impact on 
Table 1. The evaluation index of rural tourism development.

\begin{tabular}{|c|c|c|c|}
\hline \multirow{10}{*}{$\begin{array}{c}\text { Rural } \\
\text { Tourism Develop- } \\
\text { ment } \\
\text { System } \\
\text { (S) }\end{array}$} & \multirow{3}{*}{$\begin{array}{l}\text { The social life } \\
\text { of rural residents subsystem } S_{1}\end{array}$} & Rural latrine Pro $\left(x_{11}\right)$ & $\%$ \\
\hline & & Rural Water Supply Pro $\left(x_{12}\right)$ & $\%$ \\
\hline & & Rural number of hospital beds per thousand pro $\left(x_{13}\right)$ & $\begin{array}{l}\text { One bed/Ten thousand } \\
\text { people }\end{array}$ \\
\hline & \multirow{3}{*}{$\begin{array}{l}\text { The rural tourism industry scale } \\
\text { subsystem } \\
\mathrm{S}_{2}\end{array}$} & Total annual tourists number $\left(x_{21}\right)$ & Ten thousand people/times \\
\hline & & Annual income of rural tourism $\left(x_{22}\right)$ & One hundred million yuan \\
\hline & & Number farmhouse $\left(x_{23}\right)$ & household \\
\hline & $\begin{array}{l}\text { The economic standard subsystem } \\
\qquad S_{3}\end{array}$ & Farmers' consumption levels $(1978=100) \quad\left(x_{33}\right)$ & \\
\hline & \multirow{3}{*}{$\begin{array}{l}\text { The rural tourism attractions and } \\
\text { facilities subsystems } S_{4}\end{array}$} & Country hotel farmhouse and quantity $\left(x_{41}\right)$ & household \\
\hline & & Transportation Index $\left(x_{42}\right)$ & Million miles \\
\hline & & Agricultural Tourism Village $\left(x_{43}\right)$ & \\
\hline
\end{tabular}

rural tourism destination, the type of rural tourism, the development model, business management, community participation in rural tourism, rural tourism on farmers' income and other aspects of the contribution. Scholars gradually realized that the development of rural tourism is a systematic and collaborative process. Rural tourism enterprises have been developed in rural areas as an alternative to agriculture. The farm activities on a working farm are of no value to the visitors [7]. Different country have different definitions, In Malaysia, the current definition for rural tourism is rather vague, narrow and focuses on homestay Programs in rural areas [8]. Ohe et al., concluded that wider and longstanding perspective of local resource management is necessary to enhance the complementary relationship between economic gain of local brand farm products and tourism development [9]. The community attachment and community involvement are critical factors that affect the level of support for sustainable tourism development. The benefits perceived by host residents affect the relationship between community attachment and support for sustainable tourism development and between community involvement and support for sustainable tourism development [10]. The government have a crucial role as facilitators of the entrepreneurial environment, and innovation, committed, and risk-taking entrepreneurs, the destination will be flourish [11]. Its' importance of institutional support in stimulating networking has been proved, transfer of knowledge and best practice in Less Economically Developed Countries destinations (LEDC)[12]. Lu based on the actual characteristics and development of new socialist countryside construction of rural tourism, established evaluation model and the evaluation method based on the degree of coordination of rural tourism and new rural construction of socialism resident status and cognition, and finally a large flower garden betel waist Dai Ethnic Culture Ecological Village as a case empirical analysis [13]。Gao et al, coupling model is based on the coordinated development of the tourism industry and urbanization in Xi'an [14]。 Sheng et al, case in Hunan Province to study the coupling of the tourism industry and the coordination of the regional economy [15]。 Li provide an overview of the spatial patterns of travel flows and travel propensity in Pacific Asia region over a 10 -year period. The study demonstrates that the functions of travel flows and indices are complementary and provide an informative picture of spatial travel behavior and demand. [16]。Rural tourism development process has significant synergy features mainly reflected in: on the one hand, rural tourism industry is a comprehensive new industry with strong driving force enhancing the living standards of rural residents. On the other hand, the development of rural areas also provides the basis and guarantee for the development of rural tourism. The interaction between the two mutually influences each other background.

\section{INDEX AND MODEL CONSTRUCTION}

\subsection{Index Selection}

According to the synergetics, the model should include the changing of the associated elements between the subsystem of rural tourism. Rural tourism development related to many factors, from the impact of tourism development point of view, mainly related to the impact on local residents, the environment, the economy. This paper selected indicators involve four small rural residents and tourism development, namely: the social life of rural residents subsystem, rural 
tourism industry scale subsystem, the standard economic subsystem, and the rural tourism attractions and facilities subsystems. Precise quantitative system is presented in Table $\mathbf{1}$.

\subsection{Model Construction}

"Rural Tourism Development Composite System" means a whole system which have the interaction and mutual influence in the process of development. The entire system is represented as rural tourism $\mathrm{X}$, Each subsystem is expressed as: ${ }^{x_{j}}, j \in[1,4]$, The contribution of the Order parameter to the system's is expressed as Efficacy Coefficient (EC), Order parameters are indicated ${ }^{U}{ }_{j i}$, then the contribution rate of the system with its representation $E C\left(U_{j i}\right),{ }^{j}$ expressed index for each subsystem, the subsystems subscript of each order parameter is ${ }^{i}$,In using subsystems, ${ }^{U}{ }_{j i}$, Represented as $x_{j i}(j=1,2,3,4 ; i=1,2,3,4)$ Based system in the development process of the order parameter for $U_{j}=\left(x_{j 1}, x_{j 2}, \ldots, x_{j i}\right)$, where, $\mid A_{\mathrm{ji}} \leq x_{j i} \leq{ }_{j i}, i \in[1, n]$. In addition, the indicator has two kinds: one is positive index. The order degree is better when the parameter values are higher; conversely, it is lower. The other is negative index; the order degree is better when the parameter values are lower. Each subsystem power function expressions are as follows:

$$
E C\left(U_{\mathrm{ji}}\right)=\left\{\begin{array}{l}
\frac{X_{j i}-\beta_{j i}}{\alpha_{j i}-\beta_{j i}}, i \in[1, l] \\
\frac{\alpha_{j i}-X_{j i}}{\alpha_{j i}-\beta_{j i}}, i \in[l, n]
\end{array}\right.
$$

where, ${ }^{E C}\left(U_{\mathrm{ji}}\right)_{\in[0,1]}$; its value is greater and its contribution is higher in systematic order degree.

\subsection{The subsystem Ordered Model}

If took $E C\left(U_{\mathrm{ji}}\right)$ together, we can solve the order parameter's $\left({ }^{x} j i\right)$ a "total contribution" for each subsystem and orderly rural tourism degree. Generally, geometric mean method or linear weighted method has to be calculated from the degree order.

$$
E C\left(U_{\mathrm{ji}}\right) \sqrt[n]{\prod_{i=1}^{n} E C\left(U_{\mathrm{ji}}\right)} \quad j=1,2,3,4
$$

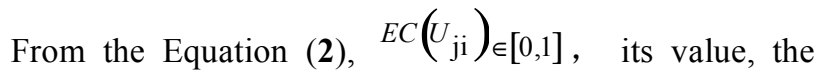
higher the degree of order subsystem, the lower the value, the lower the degree of ordering of the subsystem.

\subsection{Rural Tourism Synergy Degree Model}

Synergy degree model is suitable for the quantitative description of the system development and the order parameter as a function of the independent variables of the model. The value of the function is called Synergy Degree (SD). For a given initial time $t_{0}$, the order parameter of the system is $E C_{j}^{0}\left(u_{j}\right)$, After a period of time evolution or reach a certain moment $t_{1}$, then SD of the system are:

$C=\lambda \sqrt[n]{\left|\prod_{j=1}^{n}\left[E C_{j}^{i}\left(u_{j}\right)-E C_{j}^{0}\left(u_{j}\right)\right]\right|}$

Where,

$\lambda=\left\{\begin{array}{l}1\left[E C_{j}^{i}\left(u_{j}\right)-E C_{j}^{0}\left(u_{j}\right)\right] \times\left[E C_{j}^{i}\left(u_{j}\right)-E C_{j}^{0}\left(u_{j}\right)\right] \succ 0 \\ -1\left[E C_{j}^{i}\left(u_{j}\right)-E C_{j}^{0}\left(u_{j}\right)\right] \times\left[E C_{j}^{i}\left(u_{j}\right)-E C_{j}^{0}\left(u_{j}\right)\right] \leq 0\end{array}\right.$

Where, $C \in[0,1]$, the $C$ value, the higher the level of cooperation of rural tourism development; on the contrary, the lower. The Parameter $\lambda$ is used to determine the direction of each subsystem to coordinate rural tourism subsystem.

When $\lambda$ is 1 , it means several subsystems coordinated development, When is -1 , it means the performance of several systems in the opposite direction development or simply lack of coordination, In this paper, we selected indicators are positive indicators, $\lambda$ is 1 .

\section{EMPRICAL STUDY ON CHENGDU RURAL TOURISM}

\subsection{Sampling and Data}

In this paper, Chengdu, Sichuan Province of rural tourism for the study, the index data from the "Chengdu Statistical Yearbook" (2004-2013), "Chengdu Yearbook" (20042013), "Sichuan Statistical Yearbook" (2004-2013).

\subsection{Data Processing}

Firstly, the original data of the index standardized by the statistical software (SPSS21.0). The result was presented in Table 2 .

The object of this study is the SD of each subsystem, it can not be used past studies using specific year as the standard method, if using this method, there will be the case this year, the uneven development of different industries, If the increase will affect the data gap measure. Therefore, this study's own way of contrast, break years limit, select the highest value of the upper limit, the minimum value of the lower limit of the same indicators to reflect the value of the order parameter in a more intuitive and accurate internal system fluctuations.

Secondly, after processing the data into standardized equation (1), calculate the degree of order of each order parameter, and the results are shown in Table 3.

Thirdly, the data in Table 3 into the equation (2) and calculated the degree of order of each subsystem, then the degree of order on behalf of the various subsystems into the equation (3), resulting in the development of rural tourism complex coordination of the system, the results are shown in Table 4. 
Table 2. Standardized data of ordinal variable.

\begin{tabular}{|c|c|c|c|c|c|c|c|c|c|c|c|c|c|}
\hline & \multicolumn{5}{|c|}{$S_{1}$} & \multicolumn{3}{c|}{$S_{2}$} & \multicolumn{3}{c|}{$S_{3}$} & \multicolumn{2}{c|}{$S_{4}$} \\
\hline Year & $x_{11}$ & $x_{12}$ & $x_{13}$ & $x_{14}$ & $x_{21}$ & $x_{22}$ & $x_{23}$ & $x_{31}$ & $x_{32}$ & $x_{33}$ & $x_{41}$ & $x_{42}$ & $x_{43}$ \\
\hline \hline 2003 & 1.0828 & 0.4068 & 0.8497 & 1.8160 & 1.4527 & 1.0694 & 1.6819 & 1.1397 & 1.0596 & 1.0405 & 1.6353 & 1.3499 & 0.9722 \\
\hline 2004 & 0.8993 & 0.6806 & 0.7739 & 1.3318 & 1.5020 & 1.0069 & 1.4767 & 0.9773 & 0.9307 & 0.9278 & 1.5158 & 1.1273 & 0.9722 \\
\hline 2005 & 0.7158 & 0.9935 & 0.6980 & 1.1325 & 1.0926 & 0.9209 & 0.7170 & 0.8161 & 0.8642 & 0.7015 & 1.0688 & 0.1931 & 0.8880 \\
\hline 2006 & 0.8917 & 2.2530 & 0.6221 & 0.5138 & 0.0158 & 0.5065 & 0.9652 & 0.6521 & 0.7151 & 0.6260 & 0.2058 & 0.0574 & 0.8460 \\
\hline 2007 & 0.5170 & 0.9231 & 0.5462 & 0.5480 & 0.4933 & 0.4126 & 1.4304 & 0.3647 & 0.3535 & 0.4273 & 0.5510 & 0.8665 & 0.8039 \\
\hline 2008 & 0.2875 & 0.4928 & 0.3186 & 0.6164 & 0.3348 & 0.1257 & 0.4567 & 0.0374 & 0.0397 & 0.2707 & 0.5377 & 0.6584 & 0.5008 \\
\hline 2009 & 0.5154 & 0.2190 & 0.0607 & 0.5993 & 1.0272 & 0.1269 & 0.1109 & 0.2152 & 0.1421 & 0.1212 & 0.6262 & 1.0259 & 0.5429 \\
\hline 2010 & 1.1119 & 0.4068 & 0.4400 & 0.6278 & 0.2965 & 0.7759 & 0.2890 & 0.6350 & 0.6413 & 0.6351 & 0.5598 & 0.7737 & 0.5850 \\
\hline 2011 & 1.2572 & 0.6024 & 1.0470 & 0.6505 & 0.7161 & 1.5109 & 0.3117 & 1.2945 & 1.3251 & 1.2596 & 0.7413 & 1.1194 & 1.4268 \\
\hline 2012 & 1.5096 & 0.7979 & 2.2609 & 0.7246 & 1.1953 & 1.6282 & 0.3117 & 1.8426 & 1.8544 & 1.9779 & 0.9980 & 1.3335 & 1.4268 \\
\hline
\end{tabular}

Table 3. Each subsystem ordinal variable order degree.

\begin{tabular}{|c|c|c|c|c|c|c|c|c|c|c|c|c|c|}
\hline & \multicolumn{9}{|c|}{$S_{1}$} & \multicolumn{3}{c|}{$S_{2}$} & \multicolumn{3}{c|}{$S_{3}$} & \multicolumn{3}{c|}{$S_{4}$} \\
\hline Year & $x_{11}$ & $x_{12}$ & $x_{13}$ & $x_{14}$ & $x_{21}$ & $x_{22}$ & $x_{23}$ & $x_{31}$ & $x_{32}$ & $x_{33}$ & $x_{41}$ & $x_{42}$ & $x_{43}$ \\
\hline \hline 2003 & 0.0000 & 0.8193 & 0.0000 & 0.0000 & 0.0183 & 0.0000 & 0.0000 & 0.0000 & 0.0000 & 0.0000 & 0.0000 & 0.0000 & 0.0000 \\
\hline 2004 & 0.0708 & 0.9036 & 0.0244 & 0.1906 & 0.0000 & 0.0232 & 0.0659 & 0.0545 & 0.0442 & 0.0373 & 0.0454 & 0.0829 & 0.0000 \\
\hline 2005 & 0.1416 & 1.0000 & 0.0488 & 0.2691 & 0.1518 & 0.0551 & 0.3100 & 0.1085 & 0.0670 & 0.1123 & 0.2151 & 0.4311 & 0.0351 \\
\hline 2006 & 0.0737 & 0.0000 & 0.0732 & 0.9170 & 0.5510 & 0.2087 & 0.8505 & 0.1635 & 0.1182 & 0.1373 & 0.6992 & 0.4817 & 0.0526 \\
\hline 2007 & 0.2183 & 0.4096 & 0.0976 & 0.9305 & 0.7397 & 0.2435 & 1.0000 & 0.2599 & 0.2423 & 0.2032 & 0.8303 & 0.1801 & 0.0702 \\
\hline 2008 & 0.3068 & 0.5422 & 0.1707 & 0.9574 & 0.6810 & 0.3499 & 0.6871 & 0.3696 & 0.3500 & 0.2550 & 0.8252 & 0.2577 & 0.6140 \\
\hline 2009 & 0.6165 & 0.6265 & 0.2927 & 0.9507 & 0.9377 & 0.4435 & 0.5760 & 0.4543 & 0.4124 & 0.3849 & 0.8588 & 0.8854 & 0.6316 \\
\hline 2010 & 0.8466 & 0.8193 & 0.4146 & 0.9619 & 0.6668 & 0.6841 & 0.6332 & 0.5951 & 0.5837 & 0.5551 & 0.8336 & 0.7914 & 0.6491 \\
\hline 2011 & 0.9027 & 0.8795 & 0.6098 & 0.9709 & 0.8223 & 0.9565 & 0.6405 & 0.8162 & 0.8183 & 0.7620 & 0.9025 & 0.9202 & 1.0000 \\
\hline 2012 & 1.0000 & 0.9398 & 1.0000 & 1.0000 & 1.0000 & 1.0000 & 0.6405 & 1.0000 & 1.0000 & 1.0000 & 1.0000 & 1.0000 & 1.0000 \\
\hline
\end{tabular}

Table 4. Subsystem order degree and system coordination degree degree.

\begin{tabular}{|c|c|c|c|c|c|}
\hline & $S_{1}$ & $S_{2}$ & $S_{3}$ & $S_{4}$ & SD \\
\hline \hline Year & & & & 0.0000 & 0.0000 \\
\hline 2003 & 0.0000 & 0.0000 & 0.0448 & 0.0000 & 0.1482 \\
\hline 2004 & 0.1313 & 0.0000 & 0.0935 & 0.2607 & 0.0933 \\
\hline 2005 & 0.2076 & 0.1374 & 0.1385 & 0.2189 & 0.1483 \\
\hline 2006 & 0.0000 & 0.4607 & 0.2339 & 0.1612 \\
\hline
\end{tabular}


Table 4. Contd.......

\begin{tabular}{|l|c|c|c|c|c|}
\hline & $S_{1}$ & $S_{2}$ & $S_{3}$ & $S_{4}$ & SD \\
\hline \hline 2008 & 0.4061 & 0.5470 & 0.3207 & 0.5073 & 0.1952 \\
\hline 2009 & 0.5726 & 0.6211 & 0.4162 & 0.7831 & 0.7538 \\
\hline 2010 & 0.7252 & 0.6610 & 0.5777 & 0.9400 & 0.1479 \\
\hline 2011 & 0.8280 & 0.7957 & 0.7984 & 1.0000 & 0.2408 \\
\hline 2012 & 0.9846 & 0.8620 & 1.0000 & \\
\hline
\end{tabular}



Fig. (1). Chengdu Rural Tourism Subsystem synergetic degree.

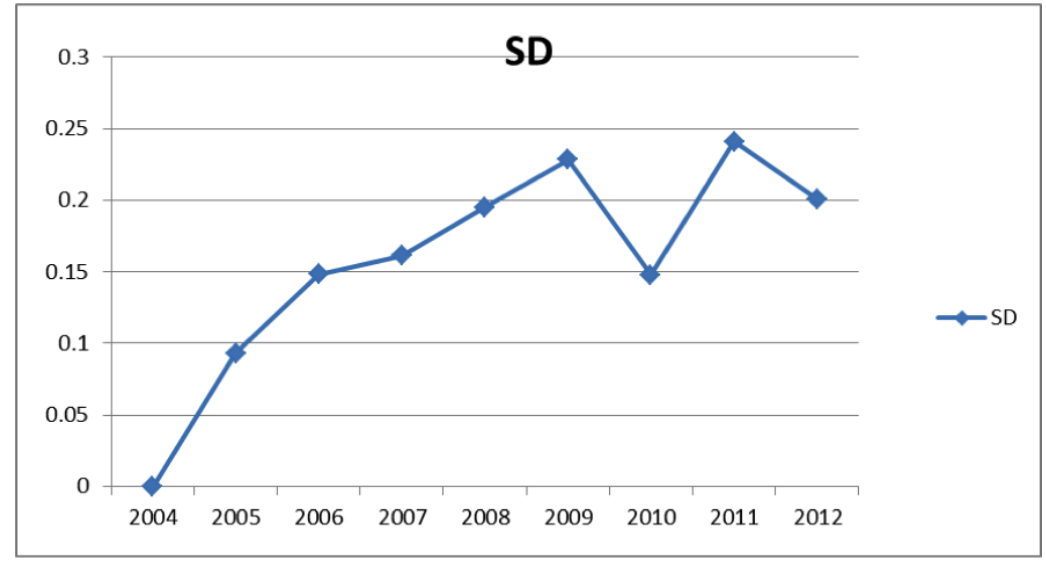

Fig. (2). Complex systems evelopment trends systems degree.

\subsection{Data Analysis}

By calculating the results, plotted in Chengdu rural tourism development trends in the various subsystems of the collaborative, Figs. (1) and (2).

The social life of rural residents subsystem (S1) showed an upward trend since 2004. The upward speed is faster in $2005,2006,2007$. It has a sharp decline in 2008 , which the 2008 earthquakes. After 2008, this subsystem continues to rise, but slow, which show aspects of living of rural tourism development in the region have reached a high degree, encountered a bottleneck stage.

The Rural Tourism industry scale systems (S2) are rapidly evolving into a geometric growth seems to have a brief decline in 2008 when an earthquake, but not decrease, followed by rapid growth.

The Economic life of rural residents subsystem (S3) rose steadily, but the rise is not excessive. This reflects the rural population did not take advantage of the development of rural tourism. The rural tourism attractions and facilities subsystems (S4) fluctuating degree of order, but the peak point appeared in the 2008 and 2009 earthquakes, which with Chengdu in 2006 introduced the "Chengdu Rural Tourism Development Plan"(2006 - 2015) and the construction of tourist facilities, but will take some time, with a lag related. And after the earthquake, Chengdu has increased in the context of the reconstruction of the development of rural tourism. 
Rural tourism makes Chengdu farmhouse rapid development of tourism facilities and other infrastructure. As can be seen from Fig. (2), Chengdu rural tourism development in the process of collaboration is not high, the highest degree of synergy is more than 0.3 , according to the general coordination of the judging criteria, are offset range. This is mainly because in the process of development of rural tourism, there is a coordinated development of various subsystems "barrel effect", ie,one or several subsystems to some extent affected the coordinated development of the whole complex system.

\section{CONCLUSIONS AND IMPLICATIONS}

In this paper, we study of rural tourism development use collaborative methods and coordination degree model to evaluate the status of the joint development of rural tourism in Chengdu. It has some theoretical significance to promote rural tourism development. At the same time, this study has its limitations, one of the only yearbook collaborative data analysis of rural tourism, yet other factors are involved, such as rural tourism development, to be the next in-depth study; the second is yet to be perfect research targets further round evaluation of rural tourism development collaborative situation.

With the economic development of China's tourism, rural tourism development as an important type. In Chengdu, rural tourism is to bring important support for the city's economic development, in order to further promote rural tourism Chengdu coordinated, orderly and sustainable development, recommends that the Government strengthens the work of the following aspects.

Firstly, the development of rural tourism should not be part of the minority who benefits the local community involvement efforts should be strengthened, so that more rural residents to benefit from tourism, improving the quality of life in rural civilian economy and improve the cultural life of rural residents. Bring real economic effect of rural tourism.

Secondly, in the process of rural tourism development should achieve coordinated development of various systems, such as strengthening the construction of tourist facilities, the development of tourism resources, so that rural tourism in many forms, not just the traditional farmhouse to eat, drink tea, playing mahjong, farmhouse only carrier must not only rural tourism.

\section{CONFLICT OF INTEREST}

The authors confirm that this article content has no conflict of interest.

\section{ACKNOWLEDGEMENTS}

This research was possible due to financial support from the Japan research center project of regional and national key research base in Sichuan province of China (NO.2014ry005), and the tourism development and research center project in Sichuan province of China (NO. LYC14-09).

\section{REFERENCES}

[1] Beijing: China Tourism Press, "China National Tourism Administration. Development of rural tourism typical case", pp. 3-6, 2007.

[2] A. Fleischer, and A. Tchetchik, "Does rural tourism benefit from agriculture?" J. Tourism Management, vol. 26, no. 4, pp. 493-501, 2005.

[3] H. Haken, "Can synergetics be of use to management theory?," $M$. Self-Organization and Management of Social Systems, Springer Berlin Heidelberg, pp. 33-41, 1984.

[4] B. Pu, and Y. Qiu, "The Synergy between City Human Resources and City Economy Development Based on the City Marketing: The Case of Chengdu," J. Mathematical Problems in Engineering, 2014.

[5] H. Knyazeva, "Synergetics and the Images of Future," J. Futures, vol. 31, no. 3, pp. 281-290, 1999.

[6] M. R. Islam, M. R. Islam, M. R. A. Beg, "Renewable energy resources and technologies practice in Bangladesh," J. Renewable and Sustainable Energy Reviews, vol. 12, no. 2, pp.299-343, 2008.

[7] A. Fleischer, and A. Tchetchik, "Does rural tourism benefit from agriculture?," J. Tourism Management, vol. 26, no. 4, pp. 493-501, 2005.

[8] V. Nair, U. T. Munikrishnan, and S. D. Rajaratnam, "Redefining Rural Tourism in Malaysia: A Conceptual Perspective," J. Asia Pacific Journal of Tourism Research, pp. 1-24, 2014,

[9] Y. Ohe, and S. Kurihara, "Evaluating the complementary relationship between local brand farm products and rural tourism: Evidence from Japan," J. Tourism Management, vol. 35, pp. 278-283, 2013.

[10] T. H. Lee, "Influence analysis of community resident support for sustainable tourism development," J. Tourism Management, vol.34, pp. 37-46, 2013.

[11] R. Komppula, "The role of individual entrepreneurs in the development of competitiveness for a rural tourism destination-A case study," J. Tourism Management, vol. 40, pp. 361-371, 2014.

[12] S. Carlisle, M. Kunc, and E. Jones, "Supporting innovation for tourism development through multi-stakeholder approaches: Experiences from Africa," J. Tourism Management, vol. 35, pp. 59-69, 2013.

[13] J. Zhan, Q. Lu, and X. Deng, "Construction of urban-rural interaction evaluation model and its application in Shandong Province," Geographical Research, vol. 4, pp. 010, 2003.

[14] G. A. O. Nan, M. A. Yaofeng, L. I. Tianshun, et al. "Study on the coordinative development between tourism industry and urbanization based on coupling model: a case study of Xi'an," J. Tourism Tribune, vol. 28, no. 1, pp. 62-68, 2013.

[15] Y. C. Sheng, and Z. P. Zhong, "Study on the coupling coordinative degree between tourism industry and regional economy: a case study of Hunan Province," J. Tourism Tribune, vol. 24, no. 8, pp. 23-29, 2009.

[16] X. Li, F. Meng, and M. Uysal, "Spatial pattern of tourist flows among the Asia-Pacific countries: An examination over a decade," J. Asia Pacific Journal of Tourism Research, vol. 13, no. 3, pp. 229-243, 2008. 